\title{
Histopathological findings of the midgut in European honey bee (Apis Mellifera L.) naturally infected by Nosema spp.
}

Paola Maiolino*, Luigi lafigliola, Laura Rinaldi, Giovanna De Leva, Brunella Restucci and Manuela Martano

*Correspondence: manuela.martano@unina.it

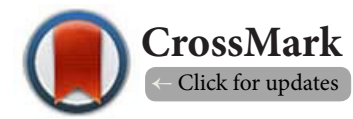

Department of Veterinary Medicine and Animal Production, University of Naples Federico II, Via Delpino, 1-80137 Naples, Italy.

\begin{abstract}
Background: Nosemosis is an infection of ventricular epithelial cells of adult European honey bees (Apis mellifera), caused by Nosema species. Until recently, it was thought to be caused only by Nosema apis. Nosema ceranae, originally found in Apis ceranae, has now been recognized also in Europe, and considered a more common infection agent than Nosema apis. This disease is present in bee colonies worldwide and it was recently proposed to be a key factor in colony collapse disorder. As the parasite can be present in honey bee colonies without causing disease symptoms, a sensitive and rapid technique for a proper diagnosis is necessary.

Findings: Adult honey samples without signs of disease were collected, observed at stereomicroscopy, necropsied, and then processed for histological examination. The examined organs didn't reveal any pathology; on the contrary, the histological examination revealed the presence of infected cells all along the ventriculus epithelium.
\end{abstract}

Conclusions: In this paper we demonstrate that histopathology is a sensitive and specific method for the detection of nosemosis and has the additional advantage of being able to provide a diagnosis in colonies without signs of disease. Possible relation with bee colony collapse is also discussed.

Keywords: European honey bee, histopathology, midgut, nosema spp.

\section{Introduction}

Nosemosis is a highly dangerous disease of adult honey bees, caused by Nosema species [1]. The genus Nosema includes protozoan parasites of the microsporidian class that are obligate intracellular parasites, transmitted between hosts as spores and have unique organs for cell invasion [2]. Nosema is able to infect all colony members including adult workers, drones and queens $[3,4]$. Nosema infection occurs mostly through ingestion of spores with food or water. The spores germinate in the midgut and the vegetative stage begins to grow in the epithelial cells of the ventriculus $[5,6]$.

Nosema apis Zander and Nosema ceranae are two species of Nosema that are reported to infect the European honey bee, Apis mellifera. For years, European nosemosis was exclusively attributed to N. apis. N. ceranae, originally found in Apis cerana, has now been recognized also in Europe, and considered a more common infection agent than $N$. apis [7]. Nosemosis causes heavy economic losses in apicultures and $N$. ceranae recently has been related to colony collapse disorder $[\mathbf{8 , 9}]$. The parasite can be present in honey bee colonies without causing disease symptoms [10]. Therefore, as infected colonies may appear normal, with no obvious signs of disease, a sensitive and rapid technique for a proper diagnosis is necessary. In this study, we describe histopathology as useful and sensitive tool for diagnosis of nosemosis, probably by N. ceranae, in naturally infected bee colonies in southern Italy.

\section{Materials and methods}

Older honey samples (15-20 days old) without signs of disease (no. $=25$ from each hive) were collected randomly between June and July 2012 in 4 hives of an apiary localized in the Caserta province (Campania region, southern Italy). Older bees were defined as bees at the hive entrance or on frames away from the brood nest. One half of samples (no.=50) were put in plastic holed containers and subsequently transferred to laboratory and stored at $-28^{\circ} \mathrm{C}$ and used to examine the presence of any 
Maiolino et al. Veterinary Medicine and Animal Sciences 2014,

microsporidian spores, as assessed by Fries et al., 2010 [7]. From each honeybee, abdomen was separated from their bodies, crushed, homogenized using a mortar and pestle and suspended in distilled water ( $1 \mathrm{ml}$ water/bee). Then, 2 or 3 drops of the homogenized solution was put on the slides and observed by a microscope with a magnification scale of $10 \times 40$, for the detection of Nosema spore. The identification of $N$. species ( $N$. ceranae and/or N. apis) was assessed using a microscope (Nikon Eclipse E-600, Tokyo, Japan) coupled with a video camera (JVC TK-C1380E Tokyo, Japan) and capturing 20 areas with a greater number of Nosema at higher magnification $(400 \times)$. Length and width of Nosema spores were calculated using an image analysis system (MONO, Imagine e Computer System, Milan).

The other half of samples (no.=50) was fixed in $10 \%$ formalin for a minimum of 2 hours until 12 hours, and used for histological processing. Before histological processing, all formalin fixed honey bees were observed under the stereomicroscope (Microscope Axioskop HBO50, Zeiss, Milan, Italy), for identification of anatomical changes. Some formalin fixed samples were divided in two halves and then embedded in paraffin wax, others were necropsied and the ventriculus, complete with the malpighian tubules, the small intestine and rectum were removed and embedded in paraffin wax. For both sections of $5 \mathrm{~mm}$ thick were stained with haematoxylineosin (HE) and observed at optical microscope (Microscope Nikon Eclipse E-600, Tokyo, Japan).

\section{Results and discussion}

The prevalence of infected bees was low. Of 100 bees examined in each of 4 hives, spores were found in 1,2 and 3 bees, respectively $(6 / 100=0.3 \%)$. Light microscopy revealed that fresh Nosema spores were 3-5 $\mu \mathrm{m}$ long and $2 \mu \mathrm{m}$ wide, regular oval shaped, highly refractive and with a dark halo around them. These characteristics made us assume that are spores of Nosema ceranae rather than Nosema apis [11].

The stereomicroscopic and microscopic observations of the sampled honey bees did not reveal any visible sign of anatomical changes. In fact there weren't signs of diarrhea and the examined organs had a normal appearance. The histological examination revealed the presence of infected cells all along the ventriculus epithelium. Parasites in various stages of development were observed in some cells at the bottom of the cytoplasm whereas in many cells, the apical cytoplasm were extremely enlarged and completely filled with spores (Figure 1). The spores were ovoid and rather uniform in shape and size and heterogeneously stained. Mature spores were surrounded by a wall and contained a basophilic elongate mass, immature spores were optically empty. In heavily infected cells, different intracellular parasitic stages such as mature and immature spores were found in the same cells (Figure 1). At the same time, mature and immature spores were seen in the gut lumen. The infected epithelial cells showed evidence of degeneration and lysis only after

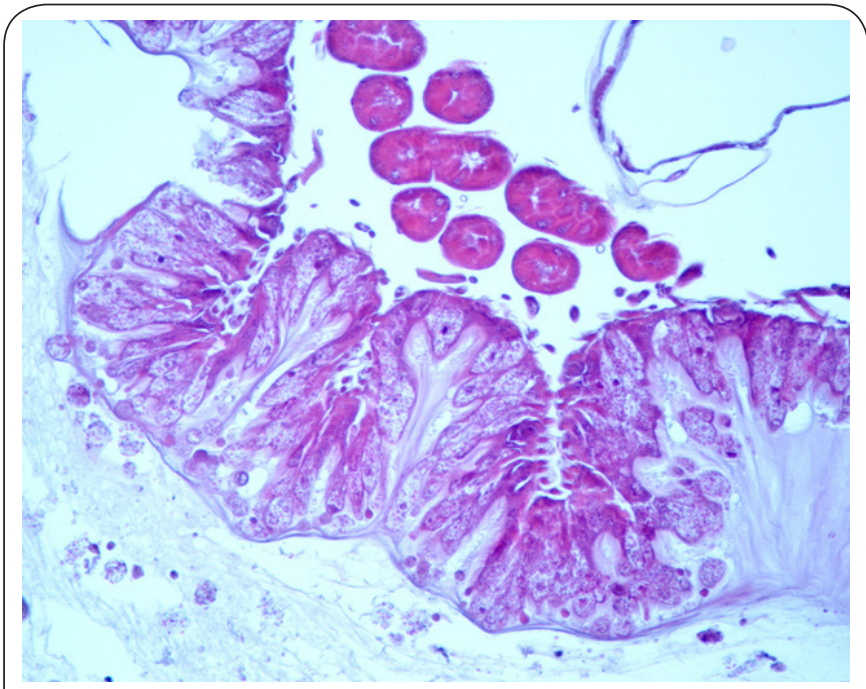

Figure 1. Midgut of honeybee: Heavily infected ventricular epithelial cells with parasites in various stages of development and spores (Haematoxylin and eosin staining, X20).

being completely filled with spores. No spores were found in any other tissue type.

In this study we report for the first time the use of histopathology as sensitive tool to diagnose Nosema spp. in naturally infected European honey bees (A. mellifera). The large number of parasitized cells and the presence of autoinfective spores reflect high infection of Nosema spp. in the tissue of the gut and indicate the rapid multiplication of the parasite in A. mellifera, suggesting a high pathological potential of parasite as reported to Nosema ceranae [8]. Although PCR detection reports [5] that other tissues may be infected by N. ceranae, in our histological sections no spores were found in any other tissue type, indicating that Nosema in bee may be a tissue specific parasite. The results obtained were comparable to those described experimentally by Higes et al., $[8,9]$ and seems to further confirm the infection with Nosema ceranae. As in our study, as reported by Higes et al., (2010) [11], clinical symptoms usually associated with Nosema ceranae infection were not observed, such as crawling bees, swelling and milky white coloration of abdomen and diarrhea. We hyposized that the highly infected bees died quickly before symptoms of the disease were evident. In our opinion, the extensive necrosis of ventricular epithelial cells would lead to ulceration with severe malabsorption of nutrients and water, effusion of tissue fluid and fast death of the infected worker bees as a result of dehydration. It was likely that the infected worker bees not returned to the colony while foraging. Once the colony could not compensate for their loss, depopulation became evident. In our interpretation of data, this disease could have a "fast incubation period" at the individual bee and a "long incubation period" at the colony level which could explain the absence of evident symptoms prior to colony death. The continuous death of highly infected bees has important negative effects on bee colonies and may 
also cause collapse colony.

\section{Conclusions}

Our results confirm as reported in previous study [12] that histopathological tool is a very sensitive and specific method for the detection of Nosemosis and has the additional advantage of being able to provide a diagnosis in colonies without signs of disease. In addition, our study seems to confirm that N. ceranae, as well as N.apis, are common infection agents in European honey bee (Apis mellifera).

\section{Competing interests}

The authors declare that they have no competing interests.

\section{Authors' contributions}

\begin{tabular}{|l|c|c|c|c|c|c|}
\hline Authors' contributions & PM & LI & LR & GD & BR & MM \\
\hline Research concept and design & $\checkmark$ & -- & -- & -- & -- & $\checkmark$ \\
\hline Collection and/or assembly of data & $\checkmark$ & $\checkmark$ & $\checkmark$ & $\checkmark$ & -- & $\checkmark$ \\
\hline Data analysis and interpretation & $\checkmark$ & -- & -- & -- & $\checkmark$ & $\checkmark$ \\
\hline Writing the article & $\checkmark$ & -- & -- & -- & $\checkmark$ & $\checkmark$ \\
\hline Critical revision of the article & $\checkmark$ & -- & $\checkmark$ & -- & $\checkmark$ & $\checkmark$ \\
\hline Final approval of article & $\checkmark$ & -- & -- & -- & -- & $\checkmark$ \\
\hline Statistical analysis & $\checkmark$ & -- & -- & -- & $\checkmark$ & $\checkmark$ \\
\hline
\end{tabular}

\section{Acknowledgement}

This study was partially supported by the Department of Agriculture of Campania Region and by the Consortium for Applied Research in Agriculture (CRAA). We thank Raffaele Ilsami for the expert technical assistance in histopathology and the beekeepers in the Regione Campania for their help in collecting the field samples.

Publication history

Editor: Akari Hirofumi, Kyoto University, Japan.

EIC: Olivier A. E. Sparagano, Northumbria University, UK.

Received: 12-Jun-2014 Final Revised: 05-Sep-2014

Accepted: 08-Sep-2014 Published: 22-Sep-2014

\section{References}

1. Bailey $L$ and Ball BV. Honey Bee Pathology. $2^{\text {nd }}$ edn. Academic Press, London, UK. 1991. I Book

2. Larsson R . Ultrastructure, function, and classification of Microsporidia. Progr. Protistol. 1986; 1:325-390. | Article

3. Alaux C, Folschweiller M, McDonnell C, Beslay D, Cousin M, Dussaubat $\mathrm{C}$, Brunet JL and Le Conte $\mathrm{Y}$. Pathological effects of the microsporidium Nosema ceranae on honey bee queen physiology (Apis mellifera). J Invertebr Pathol. 2011; 106:380-5. | Article | PubMed

4. Bailey L. The epidemiology and control of nosema disease of the honey bee. Ann. Appl. Biol. 1955; 43:79-389. I Article

5. Chen YP, Evans JD, Murphy C, Gutell R, Zuker M, Gundensen-Rindal D and Pettis JS. Morphological, molecular, and phylogenetic characterization of Nosema ceranae, a microsporidian parasite isolated from the European honey bee, Apis mellifera. J Eukaryot Microbiol. 2009; 56:1427. | Article | PubMed Abstract | PubMed Full Text

6. Liu TP. Ultrastructure of the midgut of the worker honey Apis mellifera heavily infected with Nosema apis. J. Invertebr. Pathol. 1984; 44:103105. | Article

7. Fries I. Nosema ceranae in European honey bees (Apis mellifera). J Invertebr Pathol. 2010; 103 Suppl 1:S73-9. | Article | PubMed

8. Higes M, Garcia-Palencia P, Martin-Hernandez R and Meana A.
Experimental infection of Apis mellifera honeybees with Nosema ceranae (Microsporidia). J Invertebr Pathol. 2007; 94:211-7. | Article | PubMed

9. Higes M, Martin-Hernandez R, Botias C, Bailon EG, Gonzalez-Porto AV, Barrios L, Del Nozal MJ, Bernal JL, Jimenez JJ, Palencia PG and Meana A. How natural infection by Nosema ceranae causes honeybee colony collapse. Environ Microbiol. 2008; 10:2659-69. | Article | PubMed

10. Paxton RJ. Does infection by Nosema ceranae cause "Colony Collapse Disorder" in honey bees (Apis Mellifera)? J. Apicult. Res. 2010; 49:8084. I Article

11. Higes M, Garcia-Palencia P, Botias C, Meana A and Martin-Hernandez R. The differential development of microsporidia infecting worker honey bee (Apis mellifera) at increasing incubation temperature. Environ Microbiol Rep. 2010; 2:745-8. | Article I PubMed

12. Maiolino P, Carella F, De Leva G, Rinaldi L, Cringoli G and Martano M. Histopathology as diagnostic tool for Ascospaera apis infection in apparently healthy honey bees (Apis mellifera ligustica). J. Interdiscipl. Histopathol. 2013; 1:160-162. | Article

\section{Citation:}

Maiolino P, Iafigliola L, Rinaldi L, De Leva G, Restucci B and Martano M. Histopathological findings of the midgut in European honey bee (Apis Mellifera L.) naturally infected by Nosema spp. Vet Med Anim Sci. 2014; 2:4.

http://dx.doi.org/10.7243/2054-3425-2-4 